it offers a historic background, describing how, until the late 1970s, communication was just one part of a broad natural-history data set collected by ethologists. The book ends abruptly without drawing major conclusions. The author states in the introduction that "characterising how signals encode information is only the first step in understanding animal communication". Let us hope that someone will be challenged to take the next step and combine the classification with a functional approach that considers how manipulation, deception and eavesdropping by potential friends and opponents, including predators, may have selected for specific information encoding and levels of redundancy.
These two books will provide behavioural ecologists with new ideas about the mechanisms underlying communication, which may give fresh insights into signal evolution. One can ask, as in Vibrational Communication in Animals, how signals might be designed and adjusted to deceive, to keep communication private, or to address an audience as well as a receiver. This interaction between proximate and ultimate questions is where we can achieve major advances in our understanding. Redouan Bshary is professor of behavioural ecology at the University of Neuchâtel, Institute of Zoology, CH-2009 Neuchâtel, Switzerland. e-mail: redouan.bshary@unine.ch

\title{
History out of the ether
}

\author{
Blessed Days of Anaesthesia: How \\ Anaesthetics Changed the World \\ by Stephanie J. Snow \\ Oxford University Press: 2008. 256 pp. \\ £16.99, \$34.95
}

I am no hero. All my life I have tried to avoid situations that might produce physical danger or pain; my dentist is now well trained. In my lectures on pain and anaesthesia, I advised medical students to choose their anaesthetist more carefully than their surgeon. Without good anaesthesia, surgeons could achieve few of their triumphs.

Thus I would seem an ideal reader for Stephanie Snow's new book, Blessed Days of Anaesthesia: How Anaesthetics Changed the World. But it leaves me dissatisfied. Its chapter titles are promising - 'Women, Sex, and Suffering', 'On Battlefields', 'The Dark Side of Chloroform'. Snow's knowledge of nineteenth-century medicine and society is considerable. Yet the book lacks a central concept.

Former Australian prime minister Paul Keating said that "a soufflé does not rise twice", and, compared with its predecessor Operations Without Pain: The Practice and Science of Anaesthesia in Victorian Britain (Palgrave Macmillan, 2006), Snow's new book is thin, despite its grander title. Blessed Days of Anaesthesia is also more hubristic because it directs its attention mainly towards British practice and society. Naturally the United States and the ether story must be mentioned, as should nineteenth-century war, especially because the American Civil War had great effects on medicine and wider society. Snow deals with these to some extent, but glimpses beyond her homeland are rare.
This bias is odd because the story of anaesthesia is global. In quoting from a crucial letter from the Boston botanist Jacob Bigelow to his London colleague Francis Boott in December 1846 - with its detailed account of the famous operations under general anaesthesia in the Massachusetts General Hospital - Snow omits a prophetic sentence: "This is something which will go round the world". And it did. Gwen Wilson's magisterial One Grand Chain: The History of Anaesthesia in Australia 1846-1962 (Australian and New Zealand College of Anaesthetists, 1995) gives a splendid account of the way anaesthesia spread, notably through the maiden voyage of the Pekin, which departed Southampton in February 1847 for Ceylon, and the impressive work of its surgeon, Thomas Bell, seemingly with a procedure in every port.

Snow's new book is not a real medical history, nor is it seriously concerned with medicine or society beyond England and Scotland. But it seeks to link developments in anaesthesia with changing social, philosophical, scientific and religious attitudes in those countries.

She begins by setting her account within the context of that metamorphosing national culture, but history is presented as a series of brief anecdotes. The cases presumably humanize an abstract story and show that medicine is a personal matter for patients, their families and their doctors. The book opens with the overused drama of the novelist Fanny Burney's horribly painful mastectomy in 1811, the same story with which Thomas Dormandy began his account of general anaesthesia in The Worst of Evils: The Fight Against Pain (Yale University
Press, 2006). Snow's approach has benefits but tends to diffuse the story and obscure her inchoate structure. The effect is like the recall of one's visits to great galleries through a collection of souvenir postcards: the experience is inevitably diminished.

Snow is at her most compelling when describing the criminal use of chloroform. The tale of the death of the sexually ambiguous London grocer Edwin Bartlett in 1886, the murder trial of his wife, Adelaide, and her stillcontested acquittal is engrossing. It reminds us that the rapid take-up of new technology is not always benevolent, as with modern cases of drug-facilitated 'date rape'.

The author is rightly proud of the pioneering work of her husband's ancestor, John Snow anaesthetist and epidemiologist - of whom she wrote in her previous book, "For Snow, experimental science was the anchor and mainstay of medicine". Even so, we would now describe those early anaesthetists as cavalier, experimenting on themselves around their dinner tables and rushing to use successful agents on their patients. We have far greater concerns for safety today, but not much more sense of what anaesthesia really is, because an understanding of the true nature of consciousness remains intractable. The question of serendipity versus planning in medical discovery, the need to be alert to the unexpected, the ineluctable impetus to improve the lot of patients: these are some of the tensions and fascination of medical history. Anaesthetists are, accordingly, the intellectuals of clinical medicine and obligatory pragmatists.

Blessed Days of Anaesthesia peters out in a chapter that, too hurriedly and trivially, tries to tie up anaesthetic developments in the twentieth century. This story requires a book of its own, not simply because in that century
me far safer and protean in its scope, but because modern respiratory physiology is the powerful achievement of anaesthetists.

Snow concludes with an undistinguished poem by an American physician. I recognize her point: when medicine becomes a metaphor for art we know that it has achieved a profound importance. However, I prefer to think of T. S. Eliot's image: "the evening is spread out against the sky; like a patient etherised upon a table". That is art and medicine as one, a thrilling way in which anaesthesia has changed an unexpected world.

John Carmody is a medical scientist at the University of Sydney, NSW 2006, Australia. e-mail: jcarmody@med.usyd.edu.au 